\section{COURSE REVIEW}

\section{Restoring dental implants in general practice}

I attended the three-day course on

'Restoring dental implants in general practice' at Dawood \& Tanner Academy in Central London between November 2017 and February 2018.

I originally attended an introductory five-day course on placing dental implants a few years ago, held by Dr Eddie Scher. I felt that it was important to learn the skills required and then decided to sign up for the course on restoring dental implants as well.

The 'Restoring dental implants' course comprised three separate full-day Friday sessions. Each day consisted of lectures held by both Dr Andrew Dawood and Dr Susan Tanner, external speakers (a periodontist and an occlusion specialist), discussion of our own implant cases and observation of live patients.

The course covered treatment planning, patient selection for dental implants, the Nobel BioCare brand, restoring dental implants, occlusal considerations, post-treatment care, and tips to avoid failure.

I live locally to the training academy so travelled to the course from home, and was one of nine or ten delegates. As the course consisted of one day a month over a few months I felt that it was structured well and wasn't overwhelming. Attending the course gave me the knowledge and confidence to

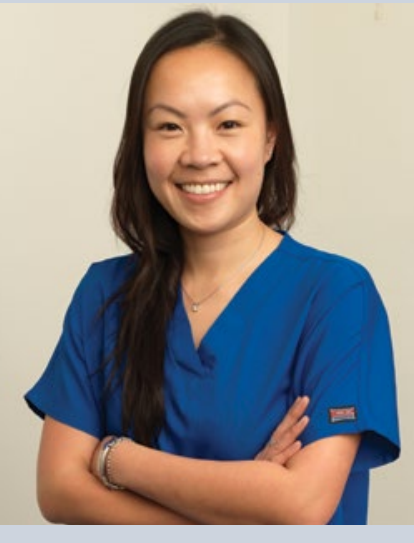

restore implants and I have since begun restoring implants on my own patients.

In the future I may undertake further training to learn how to restore more complex dental implant cases. In the meantime, my general plans are to continue enjoying my work and being able to help my patients by offering all treatment modalities with confidence.

I would absolutely encourage others to attend the course. A dental course is often all about the content, but to be taught by genuinely lovely people makes the whole experience so much better. Not only are Dr Andrew Dawood and Dr Susan Tanner experts in their fields, they are incredibly friendly and approachable too.

By Shan Lam, Dental Associate, London, UK

\title{
Further success for toothbrushing app
}

Brush DJ, the free and NHS approved toothbrushing app, has won support from Health Innovation Manchester's Momentum Fund to improve the oral health of Greater Manchester's most vulnerable children.

This project will see the innovative Brush DJ team linking in with Greater Manchester Health and Social Care Partnership (GMHSC) and the University of Manchester to develop and evaluate a digital package to support adoption of the app in high risk communities.

Dentist and CEO of Brush DJ Ltd, Ben Underwood said, 'We know that around $40 \%$ of children did not see an NHS dentist last year. By working with children's centres in parts of the country where 50\% of children start school with visible dental decay, Brush DJ will be actively reaching out to those most in need and supporting children, parents and carers to form healthy dental behaviours for life.'

Professor Anne-Marie Glenny, Head of the Division of Dentistry at the University of Manchester said, 'The University of Manchester is delighted to put our expertise behind this exciting project. We look forward to working with the Brush DJ team to provide an independent evaluation of this digital intervention. We are committed to exploring innovative approaches to improving children's oral health'

\section{New guidelines published for denture adhesives}

The Oral Health Foundation has published a new set of global science-based guidelines for denture adhesives.

The new recommendations have been launched to combat the current lack of guidance that exists for full denture wearers about the correct use of denture adhesives.

The research project reinforces the role denture adhesives (and fixatives) play in having 'best-fitting' dentures. Such benefits include better retention and stability, improved confidence and comfort and reduction or elimination of food debris beneath the denture.

The White Paper entitled Guidelines for the use of denture adhesives and their benefits for oral and general health, has been developed by a global task force of academic experts.

Having undertaken a comprehensive review of existing guidance for best use of denture adhesives, the panel found only limited recommendations and guidance in existence.

Dr Nigel Carter OBE, Chief Executive of the Oral Health Foundation said: 'The current lack of guidance on the use of denture adhesives may mean that denture wearers are left confused.

'The evidence is clear; using an adhesive can provide benefits for patients with best-fitting dentures both in terms of function, confidence and comfort.

'These new guidelines will give dental professionals the confidence to know how and when to recommend denture adhesives for maximum patient benefit.'

The guidelines have been sponsored by GlaxoSmithKline Consumer Healthcare and were announced as part of the International Association for Dental Research (IADR) 2019 meeting in Vancouver, Canada.

The task force included experts from the Oral Health Foundation and King's College London. There were also representatives from the USA, Greece, Japan and Switzerland.

The group formed to reflect the global need for advice for denture wearers given the ageing population around the world.

The new guidelines are now available at: https://www.dentalhealth.org/dentureadhesives. 